\title{
Demand for Cashew Nut Exports of Guinea-Bissau (1990-2011): VAR Model Application
}

Julio Vicente Cateia ( $\square$ juliocateia@yahoo.com.br)

Université Laval

\section{Research}

Keywords: Foreign demand for Cashew Nuts, Guinea-Bissau, VAR model.

Posted Date: July 1st, 2021

DOI: https://doi.org/10.21203/rs.3.rs-610432/v1

License: (c) (i) This work is licensed under a Creative Commons Attribution 4.0 International License. Read Full License 


\title{
Demand for Cashew Nut Exports of Guinea-Bissau (1990-2011): VAR Model Application
}

\author{
Júlio Vicente Cateia \\ Postdoc fellow, Department of Economics, \\ Université Laval \\ juliocateia@yahoo.com.br \\ 2535, Rue des Meuniers, Quebec (Quebec), Canada, G2C 1R2 \\ $+18195808745$
}

\begin{abstract}
This study aimed to estimate via VAR the reaction of the export demand for Guinea-Bissau Cashew nuts to the shocks of world income, exchange rate and of the foreign and domestic prices and of the effects of the Civil War, which occurred in the country from 1990 to 2011. The main results obtained by analyzing the impulse response function and variance decomposition, showed that changes in domestic price and exchange rates don't explain the external demand for this commodity. External demand responds to changes in global income and foreign price. Moreover, the Civil War of 1998 influenced the foreign demand. In the long run, external demand for cashew nuts doesn't react to shocks in any of the variables in the model.
\end{abstract}

Keywords: Foreign demand for Cashew Nuts. Guinea-Bissau. VAR model.

JEL Codes: F1; F14; Q17.

\section{Introction}

The world demand for agricultural commodities has increased significantly in the last four decades (UNCTAD, 2012) ${ }^{1}$, making it a feasible option for countries in transition to integrate the world economy via international trade. It should be noted that the World Bank (WB) classifies all former socialist countries that have moved to market economies as countries or economies in transition. Guinea-Bissau is a special case of this, since after independence it followed the central planning model like the former socialist bloc that supported its independence. The transition dates from the second half of the 1980s, as a result of the WB package aimed at promoting readjustment and structural reforms either in the newly independent or going through recessions countries.

This trade expansion is explained by the extraordinary boom in international commodity prices never seen since 1970. According to UNCTAD (2012), in 2003 and 2011, the boom not only broadly affected all commodity categories, but was also the biggest historically registered by that institution.

Specifically in Guinea-Bissau, from 1990 to 2011, exports of agricultural products grew at rates above $600 \%$. The representation of the Guinean agricultural sector in the early 1990s rose from $80.12 \%$ to $90.91 \%$ in 2011 (Faostat, 2015). This percentage makes the

${ }^{1}$ Guinea-Bissau cashew nut export destination data are available at: http://comtrade.un.org/data/ 
country the first place among those with the largest share of agricultural products in the export grid. This increase in the participation of the agricultural sector in the total exported is explained by cashew nut exports, which in the same period grew by around $750 \%$ (Faostat, 2015). Since 2000, this product has been responsible for more than $70 \%$ of Guinea-Bissau's exports destined for India, which is its main trading partner.

The growing external demand for cashew nuts increasingly drives the cashew nut sector and consequently the Guinean economy. In 1995, it was estimated that the areas destined to the exploitation of cashew trees ware about 103 thousand hectares. On average, every year 10,000 new hectares are incorporated into the activity, allowing production to be expanded by around $20 \%$ per year (Government official reports of Guinea-Bissau, henceforth Guinea-Bissau, 2004).

Guinea-Bissau is currently one of the world's leading cashew nut producers. In 2012 , the latest information found, the country produced US\$113,970 million, placing it in seventh position, behind Vietnam (US\$ 1,042,410), Nigeria (US\$ 732,199), India (US\$ 595,212), Ivory Coast (US\$393,890), Benin (US\$488,803) and Philippines (US\$116,014). On a global scale, the country asserts itself as one of the important players in the market, often favored by the quality of the nut produced and its favorable geographic situation, as it is a product that adapts to the tropical weather.

As a result, the Guinean government has been adopting policies to promote the export of this commodity, since customs revenues are an important contribution to the country's development policies. It should be noted that customs revenue from nut exports contributes between $35 \%$ and $40 \%$ of the total tax revenue generated since 2007. During this period, the tax on cashew nut exports was around US\$ 40 million (GUINEA-BISSAU, 2010).

It is important to highlight that, historically, the production and marketing of traditional agricultural export products, in most African countries, in Guinea-Bissau is no different, are controlled by the Government. This is done via the export quota, specific regulatory stock programs and actions organized through international commodity agreements (Diao, Dorosh and Rahmn, 2007). This state interference in the agricultural sector has two purposes, namely: to maintain the fiscal balance of the public accounts, through the revenue generated by export taxes, and to ensure, through the gricultural Policy, the growth and agriculture modernization, so that this sector maintains its participation in the GDP. Specifically in Guinea-Bissau, in 2011, the agricultural sector accounted for about $54 \%$ of GDP against $11 \%$ and $35 \%$ of the industrial and services sectors, respectively. Thus, the Government of Guinea-Bissau justifies the strong intervention in the agricultural sector, in order to guarantee the growth of the GDP, the level of employment and generate income for funding the social programs to fight poverty.

However, the government's action in the sector was abruptly interrupted with the beginning of the Civil conflict of 1998, which is a type of conflict that can have different effects on a country's economy. Imai and Weinstein (2000) argue that the Civil War can cause problems in macroeconomic policy by causing distortions in currency markets, high inflation and large budget deficits. In Guinea-Bissau, 1998 was marked by the stoppage of productive activities, when there was a drop of $6.5 \%$ in the share of the agricultural sector in the composition of GDP (WB development indicators, 2014) due to the conflict that directly affected the cashew nut harvest. 
Given the importance of cashew nut for the Guinean economy, described briefly above, this research seeks to deepen the understanding of how the demand for export of cashew nut from Guinea-Bissau reacts to shocks in the world income, exchange rate, external and internal prices. These variables appear recurrently in the literature in studies of export demand, as discussed below. Another contribution of the research is to verify whether the Civil War of 1998, which had profound impacts on the Guinean economy, also caused a structural change in Guinean exports of cashew nuts.

Thus, understanding how the country's exports react to shocks in the variables analyzed in studies of international trade flows can serve, especially to guide the Government in the preparation of more consistent economic policies precisely in those sectors that have comparative advantages. Via (2011) argues that knowing the magnitude of the elasticity of international trade (percentage changes in external income, exchange rate and prices) allows economic policy makers to deal with the inevitable, or even predictable, changes in the trade equilibrium, income, and the country employment level, especially in the case of countries with a lower level of development and with an export basket concentrated in few agricultural products, as is the case of Guinea-Bissau.

Previous studies on export demand, as detailed in Section 2, reveal some limitations, as they generally examine foreign demand from the elasticity of foreign trade, without focusing on specific products. It is known that there is inequality in terms of their weight in the export grid in different countries. This weight varies according to changes in the productive structure and foreign trade of each country. Works with the purpose of evaluating the export determinants of a product are carried out in large economies, or with some diversification in the productive structure. Another limitation of these empirical studies refers to the fact that, in many cases, they estimate the reaction of external demand to single-variable shocks. Thus, the advance of this study occurs in two main vectors: first, this study considers a priori the existence of heterogeneities in the sectors, thus seeking to model the reaction of external export demand to shocks in the main variables that determine the flow of trade between countries; second, no studies were found with the purpose of analyzing the reaction of the demand for cashew nuts in Guinea-Bissau. Thus, the achievement of this research fills this theoretical gap.

Thus, this work ends with the following questions: how does the demand for export of Guinean cashew nut react to shocks in external and internal prices, world income and the exchange rate, over the period between 1990 and 2011? Did the 1998 Civil War cause a structural change in Guinea-Bissau's export demand?

To answer these questions, we aime to: portray the importance of cashew nut exports to the Guinean economy, from 1990 onwards; estimate, via autoregressive vector (VAR), the reaction of demand for cashew nut exports to shocks in world income, exchange rate and external and internal prices betwenn 1990 to 2011; and verify whether the civil conflict in Guinea- Bissau in 1998 changed the pattern of cashew nut exports.

As hypotheses, it assumed that: the demand for Guinean cashew nut exports, from 1990 to 2011, is not influenced by the external and internal prices of this commodity, by the exchange rate and by the world income. The political instability that occurred in Guinea-Bissau in June 1998, with the subsequent weakening of institutions, did not affect the expectations of economic agents regarding the domestic production of cashew nuts, and also regarding to the demand for this commodity. 
As to contemplate these objectives, the remainder of this study is structured as follows: Section 2 mades a historical incursion into the literature. Section 3 presents the model and data, as well as the econometric procedures aimed at using the VAR model. In Section 4 analyzes the results. Section 5 Concludes.

\section{Exports Demand: related literature}

There is growing literature on export demand. Most of these publications investigate the determinants of demand as well as estimate the elasticity of demand to the selected variables, which, in general, are income, exchange rate and domestic and foreign prices.

The forerunner of research on estimating the elasticities of trade was Orcutt (1950). In essence, the work was prepared as a criticism of previous works that started from the premise that exchange depreciation is ineffective. For the author, in the post-war period, in the absence of retaliatory measures, exchange devaluation is effective, that is, it has effects on the trade balance and, therefore, on external demand (VIA, 2011).

Goldstein and Khan (1987) investigated through the simultaneous approach the price response to shocks in demand and supply for aggregate exports of industries in eight countries, in the period 1955-1970. The authors find a high price elasticity in the demand for exports, which is even greater than that obtained by previous surveys.

Cavalcanti and Ribeiro (1998) analyzed the performance and determinants of Brazilian exports in the $1977 / 96$ period, by estimating the international trade equations for basic products and manufactured products (monthly data). For the first category of products, the authors pointed out that relative prices were the main determinants of Brazilian exports, and for the second, there are signs of the existence of an exogenous growth trend, although not explicitly identified, but which can be relate to the growth of internal productive capacity or the evolution of external demand.

Recently, export demand has been the object of empirical analysis also applied to bilateral trade. Haider, Afzal and Riaz (2011) evaluated Pakistan's bilateral trade in the period 1973-2008, based on the elasticity functions of imports and exports in that country. The results of the estimates showed that income was the main determinant of demand for exports and imports. The exchange rate and income were important in determining the flow of trade between Pakistan and its trading partners.

Export demand from a specific sector has also been the object of empirical investigation (Reimer, Zheng and Gehlhar, 2012). The authors estimated the elasticity of export demand for US corn, soybeans, and wheat. They found that there was a high elasticity of demand for exports of these products. This result is statiscally significant at conventional level.

Pandey (2013) empirically examined the Marshall-Lerner condition for India, estimating equilibrium export and import elasticities using a multivariate cointegration approach. The main result achieved by this study is that the demand for exports responded positively to the variation in world income.

Monte (2012) analyzed the impacts of shocks on external and internal prices, external and internal incomes and the exchange rate on coffee exports from Espírito Santo (Brazilian state), using the VAR methodology. The study found that coffee exports reacted 
more quickly to exchange rate shocks. Exporters took more time to react to shocks in external and internal prices and in external and internal income.

Silva and Bacchi (2005) used the VAR methodology to estimate the equations that explain the main conditions of international trade in Brazilian raw sugar, based on the supply and demand curves. By adopting this procedure, the authors concluded that only foreign income, the exchange rate and the foreign price influenced the foreign trade of sugar and that the foreign price was not statistically significant in the short run.

On the other hand, the growing insertion of countries in global value chains as a result of, and mainly, the growing flow of foreign direct investment (FDI), has increased the number of studies aimed at evaluating external demand, using approaches such as the error correction model (VECM) or the vector autoregressive model (VAR), as these models facilitate the long-term analysis on the relationship between the variables. For instance, Aydin Çiplak and Yücel (2004) estimated the demand for exports and imports for the Turkish economy, for the period 1987 to 2004, using both the single-equation model and the vector autoregressive model. The authors pointed out that exchange rate and income shocks were the main determinants of the trade deficit, but not of the variation in export demand. That is, the exchange rate and income did not affect exports, but the latter were affected by unit labor costs and export prices.

Gbadebo (2006) analyzes the trade on African agricultural commodities to the United States, from 1981 to 2004 (annual data), using the VAR modeling. The author finds that the demand for exports of these commodities was positively related to variations in income in the United States and that there was price inelasticity in this country's demand in relation to exports from Sub-Saharan African countries.

Boug and Fagereng (2007) examined the exchange rate volatility and trade performance of the Norwegian economy using the VAR cointegration approach and the GARCH model. The work did not suggest any causal relationship between exchange rate volatility and export performance.

\section{The model}

This section is intended to present the proposed model for estimating the export demand for cashew nuts from Guinea-Bissau and the econometric procedures.

\subsection{The vector autoregressive (VAR) model}

VAR models were introduced in empirical studies of economics by Sims (1980) as a critique of traditional simultaneous equation models. According to Watson (1994), VAR modelING provides a flexible and treatable framework for economic time series analysis, since macroeconomic variables are generally dynamic, whose cycles of fluctuations are interrelated. In the present case, demand for cashew nut exports is affected by past and contemporary shocks of exchange rate, world income, and domestic and foreign cashew nut prices,etc.

Thus, considering a structural $\operatorname{var}(\mathrm{p})$ of order $\mathrm{p}$ :

$\mathrm{AXt}=\mathrm{Bo}+\mathrm{B} 1 \mathrm{Xt}-1+\ldots+\mathrm{BiXt}-\mathrm{i}+\mathrm{B} \varepsilon \mathrm{t}$

where $\mathrm{Xt}=(\mathrm{X} 1 \mathrm{t}, \ldots, \mathrm{Xit})$ is a vector with the endogenous variables, namely: $\mathrm{XD}$ cashew nuts exports; $P G B$ domestic cashew nuts price; $P M$ external cashew nuts price; $C A M B$ 
exchange rate, US dollar/Franc CFA; $Y M$ world income; Bo is a vector of $\mathrm{nx} 1$ constants; Bi denotes a nxn matrix of coefficients; $B$ is a nxn diagonal matrix of standard deviations; and $\varepsilon t=(\varepsilon 1 t, \ldots, \varepsilon t)$ is a vector of $n \times 1$ dimension of the independent and identically distributed random errors with zero mean and constant variance, or $\varepsilon t \sim$ i. i. d $(0, U)$, where $\mathrm{U}$ is a positive definid matrix that contains structures of variance and covariance.

All these variables were organized into a system of equations in which each one is expressed in relation to its past value and are correlated with the errors. This is the typical representation of a structural VAR, which admits the existence of the feedback effect, in the sense that each variable affects and is affected by the others, both contemporaneously and by their lagged values, and being correlated with errors (Hamilton , 1994). However, the VAR through the use of appropriate techniques and tools, minimizes this type of problem. Thus, rewriting Equation (1) in reduced form, we have:

Thus, by rewriting Equation (1) in reduced form, we have:

$\mathrm{Xt}=\varphi 0+\varphi 1 \mathrm{Xt}-1+\mathrm{et}$

where $\varphi_{0}$ is an inverse matrix " $A$ " multiplied by the vector of constants; and $\varphi_{1}$ is the matrix of coefficients

To specify the models, or choose the lag order of the stochastic processes, we use the traditional criteria of model selection, such as AIC, BIC and HQ, and then we verify whether the estimated residuals are white noise processes, using the Ljung-Box test ( $Q$ test).

It is worthy noting that in an analysis of time series, stationarity is a necessary condition to estimate them. According to Morettin and Toloi (1985, p.24), a time serie is said to be stationary if its first two moments (average and variance) are constant and if the covariance depends only on the time lag and not on the entire period that is calculated.

. In practical terms, as stated in Bueno (2008), the KPSS (Kwiatkowski, Phillips, Schmidt and Shin), Dickey and Fuller Augmented (ADF) and PP (Phillips and Perron) tests are generally used to verify if the model time series are stationary. However, due to the problem of low test power in ADF and PP statatistics, the KPSS test is increasingly preferred in the literature. For this reason, we only apply the former test.

Based Based on the results of the estimates of the VAR model, it is possible to generate the impulse response function and the decomposition of the variances of the studied times series. This is an economically fundamental analysis since the interest is focused on knowing the effects of shocks on the variables in the model. The term impulse is because it deals with disturbances that can affect the behavior of variables (response) over time. Therefore, long-term variations of these variables may result from their responses to the shocks caused - impulse response. When processes are stationary, therefore stable, shocks tend to dissipate over time. But when they are not stationary, there is an unstable trajectory in the behavior of the times series, signaled by explosive variances. Additionally, the model can also be examined using the variance decomposition. This procedure makes it possible to observe the percentage of the forecast error variance arising from each endogenous variable over the forecast horizon. This study also performs this analysis.

Meanwhile, structural break analysis can be performed using the Chow test. For Enders (2010, p.104), the Chow test can be used when the existence of abrupt changes in a particular date is suspected as a result of some event, such as Civil Conflict in GuineaBissau. The test allows us to compare regressions before the event in question and one after 
the event. If the two regressions are not statistically different, we do not rejecte the null hypothesis that there was no structural change in the data generation process.

\subsection{Data and sources}

The quantities of cashew nuts exported by Guinea-Bissau and the respective external and internal prices are sourced from Food and Agriculture Organization of the United Nations (FAOSTAT). The exchange rate data are from the Central Bank of West African States (BCEAO) and express the US dollar/CFA Franc (Guinea-Bissau currency) ratio. For the world income variable, the option was made to build a consistent proxy compatible with external sector reality. Basically, we calculate the share of the income of Guinea-Bissau's main trade partners ${ }^{2}$ in the GDP as follows:

$$
Y M=\alpha_{1} P I B_{\text {INDIA }}+\alpha_{2} P I B_{\text {SINGAPURA }}
$$

where the share values $\alpha_{1}$ and $\alpha_{2}$ represent percentages of cashew nuts destined for India and Singapore respectively. GDP data of India and Singapore come from the World Bank Development Indicators.

It should be noted that all the model variables are expressed in millions of US dollars and are estimated in logarithm differences. For the homogenization of data, the time series are transformed to semiannual frequencies, using the arithmetic mean of six months. The estimation process consists of using Stata Software (licensed by Department of Economics at the Federal University of Santa Maria - UFSM).

\section{Results}

This section presents the estimates of the proposed VAR model, as well as interprets the results obtained with the impulse-response function and the decomposition of the forecast error variance.

\subsection{Preliminary tests required in VAR modeling}

As shown in Table (1), not all times series show the same behavior over time. Some are level-integrated, ie, I(0), but the others are first-difference-integrated, ie, I(1). The XD and PM variables are both I(0). This is because the calculated statistics of the KPSS tests, 0.193 and 0.086, respectively, are lower than the critical statistics at the significance level of $5 \%$ (0.465), which leads to non-rejection of the null hypothesis (stationary times series). However, PGB and CAMB are stationary in first differences, considering a significance level of up to $10 \%$, since the statistics calculated for the KPSS tests $(-0.044$ and 0.285 , respectively) are lower than the critical statistic (0.349). The YM variable is considered stationary in first differences at the $1 \%$ significance level. Therefore, the PGB, CAMB and YM time series are I(1).

Table 1 - Unit root test results

\begin{tabular}{l|c|c}
\hline Variable & Level series & Series in first differences \\
\hline
\end{tabular}

${ }^{2}$ According to the Comtrade data (2019), India and Singapore are the main trade partners of Guinea-Bissau 


\begin{tabular}{lll}
\hline & KPSS & KPSS \\
XD & $0,193(0,465) \dagger$ & - \\
PGB & $0,567(0,465)$ & $-0,044(0,349) \dagger$ \\
PM & $0,086(0,465) \dagger$ & - \\
CAMB & $0,983(0,465)$ & $0,285(0,349) \dagger$ \\
YM & $2,596(0,465)$ & $0,523(0,736) \dagger$ \\
\hline
\end{tabular}

Source: Own elaboration. $\uparrow$ Rejection at the $5 \%$ significance level.

Notes: Values in parentheses represent critical test statistics values.

Once the unit root test is performed, sequential tests are applied to define the lag order $p$ of the VAR model. For this, we define the $P_{\text {máx }}$ equals to 3 . Through the information criteria AIC, BIC, and HQC, we observe that it is a VAR(1), since the calculated statisics of these tests were significant in the first lag, identified in this Table 2 by the asterisk.

Table 2 - Selection of VAR order

\begin{tabular}{cccccc}
\hline Lag & log.L & $\mathrm{p}(\mathrm{LR})$ & AIC & BIC & HQC \\
\hline 1 & $-1373,513$ & & $21,929^{*}$ & $22,598^{*}$ & $22,201^{*}$ \\
2 & $-1370,856$ & 0,999 & 22,279 & 23,504 & 22,776 \\
3 & $-1367,158$ & 0,999 & 22,611 & 24,394 & 23,336 \\
\hline
\end{tabular}

Source: Own elaboration.

Notes: \# is the degree of lag of the VAR system. In this table, the maximum degree of lag is $3 .{ }^{*}$ The asterisk indicates the best lag for the VAR in question.

The previous two steps are required to specify VAR model order. Based on these diagnoses, the VAR(1) model was defined as a candidate for the estimates of the time series. According to Table 3, for the estimated residuals of the $X D$ time serie, the null hypothesis (white noise) is not rejected considering a significance level of 5\%, since the statistic calculated for the Ljung-Box test (0.002) is lower than the critical statistics (18.5). For the reported values of the $Y M$ serie, the calculated statistic is also lower than the critical statistic for the Ljung-Box test, which are 0.0160 and 18.5, respectively. In this sense, the null hypothesis was not rejected and, therefore, it was inferred that the residuals are not autocorrelated. The same applies for $X D$ and $Y M$ variables.

Furthermore, when diagnosing the autoregressive conditional heteroskedasticity (ARCH) effect on the stochastic processes in question, according to the p-value shown in Table 3, the null hypothesis of homoscedasticity for all residuals of the model variables is not rejected, considering the level of significance of $10 \%$, because in both time series the p-value is very high, signaling a low probability of making the type I error, that is, rejecting $\mathrm{H} 0$ when it is true.

Table 3 - Ljung-Box test

\begin{tabular}{lcl}
\hline Variable & Ljung-BOX & $p$-valor \\
\hline XD & $0,002(18,5) \dagger$ & 0,860 \\
PGB & $0,014(18,5) \dagger$ & 0,913 \\
PM & $0,430(18,5) \dagger$ & 0,800 \\
CAMB & $4,98185 \mathrm{e}-005(18,5) \dagger$ & 0,886 \\
YM & $0,0160(18,5) \dagger$ & 0,446 \\
\hline
\end{tabular}

Source: Own elaboration.

$\dagger$ Rejection at the 5\% significance level.

Notes: Values in parentheses in the second column refer to critical values for the Ljung-Box test. 
Therefore, according to the statistical criteria analyzed above, the VAR (1) model is the best-fits model. The following subsection presents and interprets the estimated coefficients of this model, as well as analyzing the reaction of external demand to shocks in the other variables.

The times series of the present VAR model are estimated in level. Sims, Stock and Watson (1990) admit a mix of both stationary and non-stationary series by arguing that VAR model is fundamentally developed for the analysis of inter-relationships between variables.

\subsection{Estimation and interpretation of the VAR model}

Estimating the VAR(1) model in reduced form yields the estimates of the coefficients of contemporaneous relations presented in Table 4. The values of the model equations are represented in lines. In each row or column the values outside parentheses are the coefficients or estimates of the model parameters and the values in parentheses are the respective standard errors. We read the tables as the the influence of each variables in column on the variables in each row of the table, that is, the responses of the variable in a row to the shocks in the variable in a column.

Table 4 - Results of VAR(1) model estimates

\begin{tabular}{cllllll}
\hline Variable & \multicolumn{1}{c}{$X D_{t-1}$} & \multicolumn{1}{c}{$P G B_{t-1}$} & \multicolumn{1}{c}{$P M_{t-1}$} & \multicolumn{1}{c}{$C A M B_{t-1}$} & \multicolumn{1}{c}{$Y M_{t-1}$} & \multicolumn{1}{c}{ Dummy* } \\
$X D_{t}$ & 0.925 & 0.054 & 0.598 & 0.191 & 0.465 & -- \\
& $(0.044) \dagger$ & $(0.112)$ & $(0.308) \dagger$ & $(0.893)$ & $(0.171) \dagger$ & $0.855(0.499) \dagger$ \\
$P B G_{t}$ & $0.050(0.035)$ & $0.041(0.090)$ & $0.550(0.249) \dagger$ & $0.164(0.721)$ & $0.071(1.025)$ & \\
$P M_{t}$ & $0.005(0.007)$ & $0.00(0.018)$ & $0.845(0.05) \dagger$ & $0.020(0.145)$ & $-0.02(0.206)$ & \\
$C A M B_{t}$ & $-0.001(0.04)$ & $-0.00(0.011)$ & $0.016(0.031)$ & $-0.04(0.090)$ & $-0.02(0.128)$ & \\
$Y M_{t}$ & $0.002(0.003)$ & $0.002(0.008)$ & $-0,029(0,022)$ & $0.006(0.064)$ & $-0.08(0.091)$ & \\
\hline
\end{tabular}

Source: Own elaboration.

$\dagger$ Significant at the 5\% significance level.

*intercept.

As the main interest is on the response of the $X D$ variable to shocks in the other variables of the model, first, the effort is focused on interpreting this variable. That said, observe that the signs of the coefficients of the $P G B$ variable are not as expected and are also not statistically significant, considering a significance level of $5 \%$. This points out that shocks in this variable are not capable of influencing the trajectory of external demand for Guinean cashew nuts. In other words, the external demand for this commodity does not respond to variations in its internal price. Likewise, the coefficients of the CAMB are nonsignificant at the 5\% significance level, also indicating that foreign demand for Guinean cashew nuts does not respond to exchange rate shocks.

First of all, there are instabilities in the model's parameters, signaling an impact of the Civil Conflict on the selected data. This situation is confirmed by applying the Chow test to assess the structural break in external demand for cashew nuts. The calculated Chow test statistic is $\mathrm{F}_{5,32}=5.78$, which is highly statistically significant at $1 \%$ suggesting that Civil Conflict has affected Guinea-Bissau's cashew nut exports, as also captured by the statistic significant at $5 \%$ of the intercept (first row and last column).

The $P M$ variable presents statistically significant coefficients, at a 5\% level, suggesting that a variation in the international price tends to cause changes in the demand for cashew nut exports. A $1 \%$ variation in the external price causes a contemporaneous 
variation of about 0.60 percentage points in cashew exports. This relationship has been verified since the beginning of the decade, when the quantum of exported cashew nuts began to follow the growing trends in its external price. For example, the $346.15 \%$ growth in cashew nut exports between 1990 and 2000 is also explained by the favorable external price of this commodity, which in the same period increased by $9 \%$, a trend that was repeated in subsequent years .

Similarly, the $Y M$ estimates were significant, considering a significance level of $5 \%$, which indicates that a $1 \%$ increase in foreign income tends to provoke a contemporary increase of 0.45 percentage points in cashew exports.

When analyzing current exports in relation to their flow in the immediately previous period, it can be seen that this variable has a statistically significant coefficient, at level of $5 \%$, indicating stability in the behavior of Guinean exports. That is, a $1 \%$ increase in external demand in the previous period leads to an increase of more than 0.9 percentage points in the current flow of exports.

The model's estimates also showed that there is a dynamic relationship between the domestic cashew nut price in the current period and the external cashew price in the previous period. This relationship is highly significant, from a statistical point of view, since a variation of $1 \%$ in the external price in the previous period causes a contemporary change of 0.55 percentage points in the internal price. This relationship can be analyzed in light of the efficiency of the international cashew nut market. The significance of the coefficient suggests that the cashew nut market is an integrated market and information flows quickly between the main producers, in such a way that there are price transmission effects, signaling that the Single Price Law (SPL) may be valid, when analyzing the dynamics of price formation in this market in a given period of time.

In addition, the external price of the previous period has an influence on the current external price. This effect is also suggested by the high significance of the estimated coefficient of this variable, indicating that a $1 \%$ increase in the external price tends to provoke contemporaneous variations in this price by about 0.84 percentage points. The slow price adjustment can result from several factors: (i) supply shocks may take time to have an effect on the product market; (ii) the signals emitted by the market are not instantly perceived, that is, agents take time to adjust prices because the information is not fully accessible or is slowly perceived and; and (iii) after the sales or purchase contracts are signed, their revision may involve high costs that are not economically negligible.

Thus, although not all variables that influence Guinea's foreign trade have statistically significant coefficients, in general, the estimates of the proposed model are robust, since all external variables influenced the behavior of demand for exports. In fact, a comparative analysis with the results of estimates from the revised literature would be necessary. However, most of the studies reviewed in Section 2 do not focus on a specific product. The studies that aimed to assess the behavior of exports of a specific product were carried out at state levels within a country, or at levels of countries with characteristics totally different from those observed in Guinea-Bissau, which makes comparison so difficult.

\subsection{Impulse-response function and variance decomposition}


To capture the reaction of vectors to shocks of one standard deviation in another vector, we generate the graphs of the impulse-response function, which are depicted in Figure 1. These shocks can come from changes in the external situation (related to changes in world income and/or external prices), or from the internal situation (increase or decrease in the harvest due to purely natural factors and/or internal political instability experienced in the parents).

The impulse-response function graphs, Figure 1, comprise a forecast period of twelve semesters. What stands out, in general, is that the assimilated of the shocks until the fourth semester. The first Figure (a) shows that shocks in the external demand variable itself had negative effects in the first semester. However, these effects quickly dissipated over time, as, from the second half of the year onwards, the processes resumed their longterm trajectories.

It is possible to observe that the shocks in the internal price of cashew nut (PGB) variable - Figure (b) in Table 1 - caused negative effects on the external demand in the first semester, which was expected, since Guinea-Bissau is not capable to control the international price. Thus, the increase in the price of cashew nuts in Guinea-Bissau's internal market makes the external demand shift to other competing markets, generating internal pressure on the PGB, which makes it resume its long-term trajectory. This situation is evidenced in the graph of the impulse-response function, which reveals that domestic price shocks have statistically significant effects on external demand only in the first semester, from the second semester onwards the internal price shocks have completely dissipated.

The same interpretation holds for the exchange rate - Figure (d). In other words, exchange variations have negative effects on demand only in the first semester. After this period, the shocks stabilize, that is, external demand follows its long-term trajectory, regardless of any distortions in exchange markets.

In relation to external factors, the impulse-response function, Figure (c), indicates that in the first semester the external demand variable (XD) reacts negatively to external price shocks (PM). This suggests that if external agents have expectations regarding important variations in the international price, they will not, at present, sign new purchase contracts in the expectation that in the future the external cashew nut markets will return to normal functioning. This fact can be evidenced from the second half of the year onwards, a period in which the mechanisms that govern these markets make exchanges feasible, that is, when external demand reacts positively to external price shocks. However, after this period, external price shocks dissipated, while demand for cashew nuts followed its long-term trajectory.

It is also possible to verify that shocks to world income (YM), Figure (e), positively affected the demand for exports in the first half of the year, thereafter the shocks dissipated, that is, the demand for exports was no longer affected by variations in foreign income.

Figure 1 - Response to impulse on cashew nut exports 


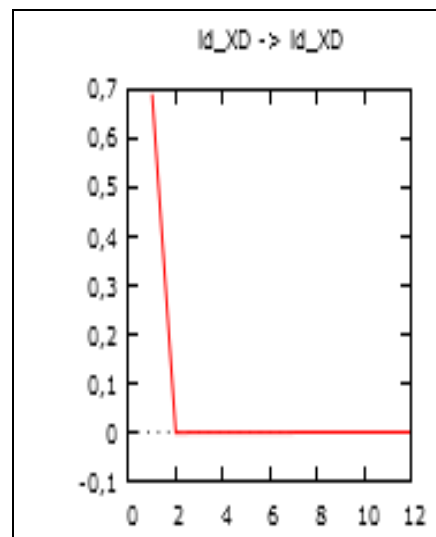

(a)

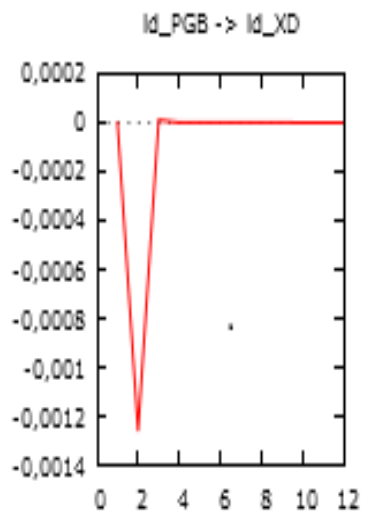

(b)

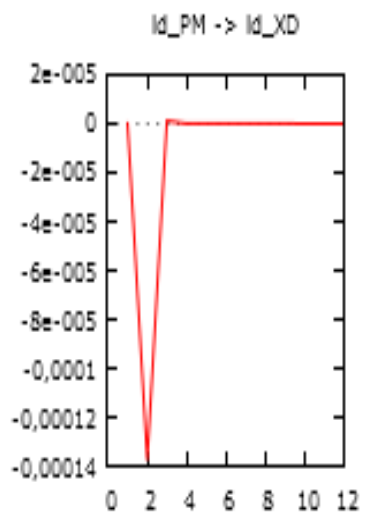

(c)

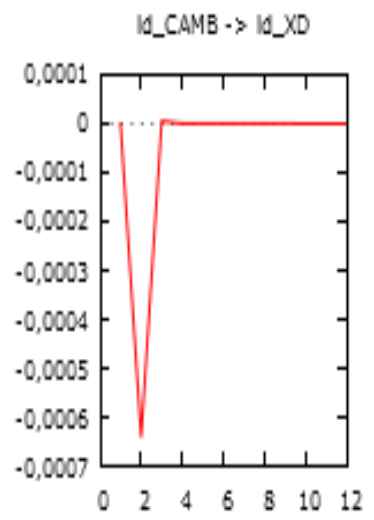

(d)

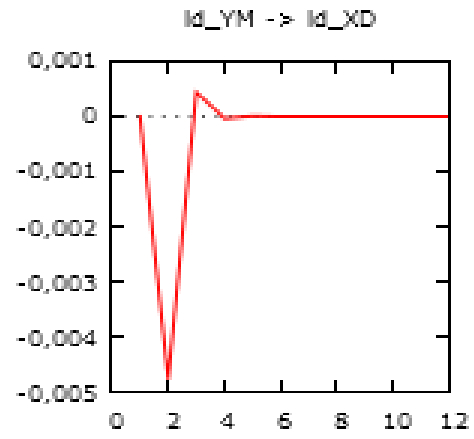

(e)

Source: Own elaboration.

Note: Id: $\log$ differences.

Table 5 presents the variance decomposition estimates over a forecast time horizon of eight semesters, that is, four years. It is noted that in the first half of each year, the variance in the forecast error of demand for cashew nut exports is not explained by exchange rate volatility, by variations in external and internal prices and by world income, but by external demand itself., that is, the variance of the forecast error was largely explained, throughout the entire period, by the external demand for cashew nuts, whose weights ranged from $52.1195 \%$ to $63.1706 \%$. However, starting in the second half of the year, internal and external prices, exchange rate and income variables gained importance in explaining the variance of the external demand forecast error.

Table 5 - Decomposition of the forecast error variance of demand for cashew nut exports

\begin{tabular}{lcccrc}
\hline Period\# & XD & PGB & PM & CAMB & YM \\
\hline 1 & 100,00 & 0,00 & 0,00 & 0,00 & 0,00 \\
2 & 63,1706 & 0,00 & 0,365 & 0,016 & 36,4484 \\
3 & 58,656 & 0,006 & 1,108 & 0,021 & 40,2090 \\
4 & 58,2582 & 0,022 & 2,149 & 0,024 & 39,5468 \\
5 & 56,5716 & 0,045 & 3,401 & 0,025 & 39,9574 \\
6 & 55,0845 & 0,075 & 4,786 & 0,025 & 40,0295 \\
7 & 53,6045 & 0,108 & 6,233 & 0,025 & 40,0295 \\
8 & 52,1195 & 0,142 & 7,684 & 0,025 & 40,0295 \\
\hline
\end{tabular}


Source: Own elaboration.

\#Forecast period or horizon.

The weights of the domestic price and the exchange rate in explaining the forecast error variance were relatively low, as the domestic price explaines by about $0.006 \%$ to $0.142 \%$ the forecast error variance over the entire forecast horizon, while the exchange rate explaines by about $0.016 \%$ to $0.025 \%$.

On the other hand, external price and income had statistically significant weights in explaining the forecast error variance. The external price has an increasing weight, varying from $0.365 \%$ to $7.684 \%$ during the established period, while income shares vary from more than $36 \%$ to $40 \%$. Thus, it can be said that external income had a significant percentage in explaining the variance of the forecast error in demand for cashew nut exports from Guinea-Bissau. However, its percentage remained constant from the sixth semester onwards, signaling that its effect resides mainly in the short and medium term. In the long run, given the seasonality of the product, external demand does not respond to changes in world income.

In short, the result of the estimates above demonstrates that the demand for cashew nuts exports is not affected by the variation in the domestic price of this product, nor by exchange rate volatility. Over the forecast horizon, it is observed that only changes in world income statistically impact changes in external demand. However, it can be said that the impacts of external income on demand occur in the medium-term horizon (two years).

Based on this result, which, in general, is consistent with concentional economic literature, is relevant to approach the result of each of the model's variables, given the peculiarity of the Guinean economy. That said, a possible explanation regarding the nonreaction of external demand, including in the short term, to shocks in the domestic price of cashew nuts lies basically in the fact that domestic demand is of little economic significance. Since the beginning of the 1990s, the export of cashew nuts has followed its production trend and, each year, more than $90 \%$ of the quantity produced is exported. In this sense, it is believed that the domestic price is not a vector capable of changing the orientation of Guinean cashew nut production from the foreign to the domestic market.

However, in the medium and long term, changes in the exported quantity have little to do with variations in external prices. This is because there are few countries in the world that produce this commodity and most production is aimed at serving the domestic market. For example, today, India, in addition to being one of the main world producers of cashew nuts, has been experiencing, since the beginning of the 2000s, an increase in the production of this commodity. However, Indian production is insufficient to meet its own demand, which makes this country the Guinea-Bissau's main trading partner. Thus, fluctuations in international demand are often dictated by the need for the product itself rather than by its current price in the international market.

The second explanation could be found in gravitational trade model. Because if the distance between countries is negatively related to the flow of trade between them, it is expected that the growing Indian demand is associated with the calculation made in terms of minimizing transport costs, since Guinea-Bissau is more closer to that country than other markets, such as Brazil, so that external demand reflects these aspects more than changes in external prices. 
Regarding the exchange rate, it is argued that, as Guinea-Bissau is part of the West African Economic and Monetary Union (UEMOA) and the macroeconomic policies of these countries are harmonized for all member countries, the current exchange rate in Guinea-Bissau, in a given period, is the same as in other countries. Thus, as Guinea-Bissau does not have the autonomy to determine the "optimal" exchange rate to stimulate exports, the contemporary reaction of external demand for Guinean exports would be a function of shocks in other variables, especially the income variable.

It is worth noting that the expansion of incomes in emerging countries has been accompanied by an increase in demand for inputs to sustain the growth rates of their economies, which in recent years have reached expressive averages. India and Singapore have increased their economic growth rates in recent years, something around 8\% a year. As a result, they not only increased their external investments, but also managed to integrate themselves into global supply chains in search of intermediate goods. In relation to Guinea-Bissau, this phenomenon can be verified by the volume of exports to those Asian countries, explained much more by the expansion of income in these countries than by the crisis of the former main trading partner, Portugal.

However, the effect of income on exports is limited in the short and medium term. In fact, this stability in the parameters of Guinea's foreign trade, in the long run, depends a lot on the current situation in the country, which, after gaining independence, faced long periods of political instability and institutional weaknesses. Thus, although the variation in world income has effects on the external demand for Guinean cashew nuts, in the short and medium term, over time, the flow of foreign trade in Guinea-Bissau also reflects the prevailing internal circumstances, such as the absence of an institutional system with the ability to define trade policies and aimed at promoting exports. In fact, as there are no defined international trade policies and the lack of infrastructure has been the main cause of the product's moisture, trading partners have strongly uttered threats, even of returnable, as has been frequent, causing a decrease in the internal price to facilitate its drainage. Therefore, the country's currencies suffer strong extroversions, affecting the population that depends on the external sector's income. As a result, despite the growth of income in emerging countries causing an increase in demand for agricultural inputs in recent decades, the institutional weakness of Guinea-Bissau, combined with the lack of internal infrastructure, which allow the storage and treatment of the product, has hindered trade flows.

\section{Conclusions}

The objectives of this work were to evaluate whether the demand for export of cashew nuts from Guinea-Bissau reacts to external and internal price shocks, exchange rate and world income, using the autoregressive vector model and to analyze whether there was a structural break after 1998 military conflict.

Based on the VAR(1) results, some initial hypotheses were confirmed, but in some cases others were not confirmed. First, it was seen that the demand for export of Guinean cashew nuts is not affected by the variation in the domestic price of this product or by the exchange rate. Contrary to the initial hypothesis, such demand is influenced by the variation in external prices and world income. Second, when analyzing the impulseresponse function, it was noticed that the shocks of the variables prices, exchange rate and 
world income were acute from the second half of the year onwards, but when the harvest ended, they dissipated. This suggests that despite the positive relationship in the first periods between external demand and changes in world income, the same may not hold in the long periods, given the seasonality of the product.

This result was also evidenced through historical decomposition of the variance of the external demand forecast error, where in the second semester there is an increase in the percentage of world income in explaining the external demand for Guinean cashew nuts. But over time this percentage remains constant, thus indicating that the variation in world income influences external demand only in the short and medium term. Finally, it was also concluded that the demand for exports was affected by the 1990 conflict, which had a negative impact on the flow of international trade of cashew nuts, causing a drop in the exports volume by the country.

Therefore, based on these results, it is suggested that the way in which the country entered international trade, with only a single important product for the generation of foreign exchange and employment, naturally places it in a situation of external vulnerability, since that the country's exports depend much more on external factors, such as world income, than on internal ones, such as exchange rate policy. Confirmation of this hypothesis requires more detailed studies. What is found in the results of this research is an indication that some internal factors, including exchange rate policy, had no effect on external demand, but others, such as political instability, affected demand for Guinean cashew nuts. However, further studies are required to analyze how the design of the institutional situation present in Guinea-Bissau has contributed to the country's economic development.

\section{Declarations}

Ethics approval and consent to participate

- This manuscript has never been published or considered for publication in any other means of dissemination.

- Consent to participate no applicable

Consent for publication

- I authorize the publication of this manuscript in accordance with the policies of the Journal of Economic Structures

Availability of data and materials

- Data will be made available to the Journal of Economic Structures

Competing interests

- Not applicable

Funding

-Not applicable

Authors' contributions

- Not applicable

Acknowledgements

-Not applicable 


\section{References}

AFZAL, M. (2005), Demand and Supply of Export in Pakistan - A Disequilibrium Model. The Labore Journal of Economics, 10 (1), p.49-64.

ARIZE, A. C. (1987), The supply and demand for imports and export in a simultaneous model. Applied Economics, 19(9), p.1233-1247.

BCEAO. <<Exchange rate database>>. http://edenpub.bceao.int, 2020.

BOUG, P. E FAGERENG, A. (2007), Exchange rate volatility and export performance: A Cointegrated VAR Approach. Statistics Norway, Research Department. Discussion Papers, $n^{\circ} 522$,

BUENO, R. L. S. (2008), Econometria de séries temporais. São Paulo: Cengage Learning.

CAVALCANTI, M. A. F. H.; RIBEIRO, F. J. (1998), As Exportações Brasileiras no Período 1977/1996: desempenho e determinantes. IPEA Discussion Paper, nº 545.

EHRHART, H.; GUERINEAU, S. (2012). <<Commodity price volatility and Tax revenues: Evidence from developing countries $>$. https://cerdi.org/uploads/ed/2011/2011.31.pdf, 2015.

ENDERS, W. (2010), Applied Econometric Times Series. United States of America: Wiley.

ENGLE, R. F; GRANGER, C. W. J. (1987), Co-integration and Error Correction: Representation, Estimation and Testing. Econometrica, 55 (2), p.251-228.

FAO (Food and Agriculture Organization of the United Nations). (2015), <<Database>>. http://faostat.fao.org/site/342/default.aspx, 2020.

GOLDSTEIN, M.; KHAN, M. S. (1978), The supply and demand for exports: a simultaneous approach. The Review of Economics and Statistics, 60 2) p. 275-286.

GUINÉ-BISSAU. (2010), < B Beyond Cashew Nuts: Diversification through trad $>$. http://wwwwds.worldbank.org/external/default/WDSContentServer/WDSP/IB/2011/02/1 0/000333038_20110210233340/Rendered/PDF/595620ESW0PORT1Main0Report01PU BLIC1.pdf.

Hamilton, J. G.1994. Time Series Analysis. Princinton UNiversity Press. 816pg

RIAZ, F.; AFZAL, M.; HAIDER, J. (2011), Estimation of import and export demand functions using bilateral trade data: The case of Pakistan. Business and Economic Horizons, 6 (3), p.40-53. 
IMAI, K.; WEINSTEIN, J. (2000), Measuring the Economic Impact of Civil War. CID Working Paper, $\mathrm{n}^{\circ} 51$.

JAMAL, H. (2008), Traditional Export Demand Relation: A Cointegration and Parameter Constancy Analysis. International. Journal Of Applied Economics and Quantitative Studies, 5 (2), p.41-65.

KONANDREAS, P; BUSHNELL, P.; GREEN, R. (1978), Estimation of Export Demand Functions For U.S. Wheat. Western Journal of Agriculture Economics, p.39-50.

MONTE, E. Z. (2012), Exportações de café do Espírito Santo Aplicação da metodologia VAR. Revista de Política Agrícola, n. 4, p.106-119.

MORETTIN, P. A., TOLOI, C. M. (1985), Previsão de séries temporais. São Paulo: Atual.

MURTEIRA, B. J. F.; MÜLLER, D. A.; TURKMAN, K. F. (1993), Análise de sucessões cronológicas. Lisboa: McGrauw Hill.

ORCUTT, G. H. (1950), Measurement of Price Elasticities in International Trade. The Review of Economics and Statistics, 32 (2), p.117-132.

PANDEY, R. (2013), Trade Elasticities and the Marshal Lerner Condition for India. Global Journal of Management and Business Studies, 3 (4), p. 423-428.

REIMER, J. J.; ZHENG, X.; GEHLHAR, M. J. (2012), Export Demand Elasticity Estimation for Major U.S. Crops. Journal of Agricultural and Applied Economics, 44 (4), p. 501-515.

SHIGEYUKI, H. YOICHI, M. (2009), Empirical Analysis of Export Demand Behavior of LDCs: Panel Cointegration Approach. Munich Personal RePEc Archive, n.17316, setembro.

SILVA, M. V. S. S.; BACCHI, M. R. P. B. (2005), Condicionantes das exportações brasileiras de açúcar bruto. Agricultura em São Paulo, São Paulo, 52 (2), p. 99-110.

SIMS, C. A. Macroeconomics and Reality. (1980), Econometrica, v.48 (01), p. 01-48.

UNCTAD.(2012), <<Commodities and Development Report >>. http://unctad.org/en/PublicationsLibrary/suc2011d9_en.pdf, .

UNITED NATIONS COMTRADE. (2015) <<Bilateral trade flow data>> http://comtrade.un.org/data/>. 
VIA, A. (2011), Estimating Price Elasticities in International Trade: is the Empirical Evidence Beyond Proof?. http://www.etsg.org/ETSG2011/Papers/Via.pdf.

WATSON. M. W. (1994). Vector Autoregressions and Cointegration. Chicago: Handbook of Econometrics.

WB (World Bank. (2020), <<Database>>. http://data.worldbank.org/. 